\title{
LANDSCAPE AND TRAFFIC FACTORS AFFECTING ANIMAL ROAD MORTALITY
}

\author{
Shyh-Chyang LIN \\ Department of Civil Engineering and Engineering Management, National Quemoy University \\ Jinning, Kinmen, Taiwan
}

Submitted 1 Apr. 2015; accepted 18 Sep. 2015

\begin{abstract}
Roadkill is a significant indicator in realizing the impacts of roads on adjacent ecosystems. This study undertakes a comprehensive survey of roadkills in Kinmen (Taiwan) and analyzes their causes. Two models, Traffic Flow Model and Geometric Model, combined with animal road-crossing behaviors, are used to derive survival probability. Survey results and model predictions yield similar results for moderate traffic flow and agree in bird and small mammal roadkill frequency prediction. It is found that traffic volume, adjacent landscape and road condition are the major contributing factors related to roadkills. Higher traffic volume near habitats always augments the probability of roadkill; however, roadside trees, adjacent landscapes, and road longitudinal slope also affect the probability of successful crossing by small animals, especially birds. This study also proposes measures, to be applied to future road planning and design, aimed to lower roadkill probability.
\end{abstract}

Keywords: roadkill, ecological conservation, traffic flow theory, Kinmen, geometric model.

\section{Introduction}

The globalization of regional development has been dramatically destroying ecological habitats and decreasing global biodiversity. Harmony and coexistence between nature and human beings are in jeopardy. The impact of human development on the global ecosystem is unprecedented. Wilson (1989) estimates that 10,000 to 15,000 species become extinct worldwide each year; 34 species disappear on the earth each day due to the destruction of forests and animal habitats. The most severe impact by humans on ecosystems is the construction of road networks. Road construction directly affects the adjacent habitat and leads to increased human invasion and development. Roads impact ecosystems through: destruction of habitat, disturbance to animals, roadkills, and barrier effects (Seiler 2001). Although some positives, such as providing corridors for animal movement (Adams, Geis 1983; Seiler 2001), can be derived from the presence of roads, they cause much more harm to ecosystems than good. Five major factors to be considered when planning ecologically friendly roads are: the road itself (width, pavement, mitigation measures), traffic (vehicle speed, traffic volume), road verge (width, shape, vegetation), adjacent land use (forest, community, agriculture), and species (size, weight, food web, territory, migration characteristics, dispersion ability, and rarity) (Jaarsuma, Willems 2002).

The patterns of avian-vehicle collisions are difficult to assess because they are three dimensional and the birds' crossing methods vary. Granivorous and omnivorous birds are more likely to collide with cars as they forage on the roads and are attracted by the heat of roads (Dhindsa et al. 1988). Avian roadkills happen more frequently when birds are chasing each other and flying low over roads (Eritzoe 2002). Some research suggests that accidents involving birds are rare at vehicle speeds of less than $80 \mathrm{~km} / \mathrm{hr}$ (Nankinov, Todorov 1983) and can occur only at vehicle speeds over $100 \mathrm{~km} / \mathrm{hr}$ (Dhindsa et al. 1988). Based on the results of this survey, this fact is questionable and needs further investigation.

Though it is believed that small animal collisions have a minor effect on human safety, drivers can be seriously injured due to avoiding hitting animals. One surprising fact is that non-forest areas have more roadkills than forested or reserved areas (Gunther et al. 1998). The ecotones between natural and developed areas are the places with higher probability of roadkills. Refuse and grains dropped

Corresponding author: Shyh-Chyang Lin

E-mail: sclin@nqu.edu.tw 
from vehicles are fatal attractions (Slater 1994) to wildlife as they are often hit by oncoming traffic (Dhindsa et al. 1988). The impacts of roadkills upon animal populations vary depending on the sensibility of the species. A survey in Yellow Stone National Park shows that only 2\% of the estimated population of wolves and mule deer, and $1 \%$ of large mammals were killed by vehicles each year (Gunther et al. 1998). However, the impact of roadkill on the population of rare or endangered species is still unknown but may be an important issue in conserving those species.

It is the responsibility of transport planning engineers to reduce the ecological impact roads have and use mitigation measures as tools in ecological conservation. The basic, necessary information for road-related ecological data is the locations of roadkill hot spots and their causes. With that ecological information, implementation of ecological friendly transportation systems can be achieved. Most factors in animal casualties are biological aspects; however, certain engineering designs, improper construction practices, or conflicts between engineering codes and conservation policies may potentially lead to a massive number of roadkills. Therefore, some roadkills can be prevented simply by changing engineering designs and methods. This, however, is usually overlooked by engineers because few studies regarding roadkill prevention have been undertaken by engineering researchers or scholars. This study models roadkill probability by applying traffic flow theory and analyzes the effects of road attributes, roadside trees, traffic volume, and adjacent landscapes on the frequency of roadkill. Then, field investigation data is used to test the models. Finally, the research results and models of this study are used to propose measures to mitigate the probability of vehicular-wildlife accidents from an engineering point of view.

\section{Study site and methods of surveying roadkill}

In this study, roadkill research is carried out on Kinmen Island, Taiwan: an island county near Mainland China with abundant ecological features. With a diverse landscape, high road density, and the abundance of birds and small mammals, roadkills in Kinmen happen with great frequency. This makes it an ideal place for roadkill investigation. Therefore, the results of the research show the biological correlation between habitats and roadkill hot spots as well as the influence human development has on the probability of animal casualties. For a more comprehensive survey, 8 major roads are selected for roadkill investigation: Central Road (CR, $11.86 \mathrm{~km})$, Wuandaou E. Road (WDE, $3.25 \mathrm{~km}$ ), Wuandaou W. Road (WDW, 12 $\mathrm{km}$ ), Wuandaou N. Road (WDN, $12.45 \mathrm{~km}$ ), Jiochan Road (JR, $1.1 \mathrm{~km})$, Banlin Road (BL, $0.74 \mathrm{~km})$, University Road (UR, $0.5 \mathrm{~km}$ ), and Gaoyaung Road (GY, $4.1 \mathrm{~km}$ ), totally 46 $\mathrm{km}$ as shown in Figure 1. The roads cover the four townships in Kinmen; each with distinct adjacent landscapes, traffic flows, and speed limits are distinct.

The field investigation was carried out November 1 , 2005 to October 31, 2006. Researchers rode motorbikes at speeds of about $40 \mathrm{~km} / \mathrm{hr}$ along the 8 roads once a day, every day. Once an animal body was spotted, they: took a picture of the body, initially identified the species, used a laser distance measurer to check the location, removed the body, reconfirmed the initial identification of the species, and buried it on the road side to avoid double counting. After 12 months of investigation, roadkill hot spots were identified and their associated factors, such as road pattern, adjacent landscapes, traffic flow, road slopes and vehicle speeds, are also studied. 466 roadkills were discovered. Their locations are shown in Figure 1. The results of the survey are summarized in Table 1 and roadkills on each investigated road are shown in Table 2 . The majority of identified animal bodies are birds (206), rodents (143), and amphibians (mostly toad, 55).

Central Road, with the highest traffic volume and speed limit, has a substantially lower animal accident rate. Therefore, traffic volume and vehicle speed may not be the only factors that affect roadkill frequency. They may act as ecological filter (McDonald, St. Clair 2004) or absolute barriers (Bennett 1992; Forman 1995) to animals

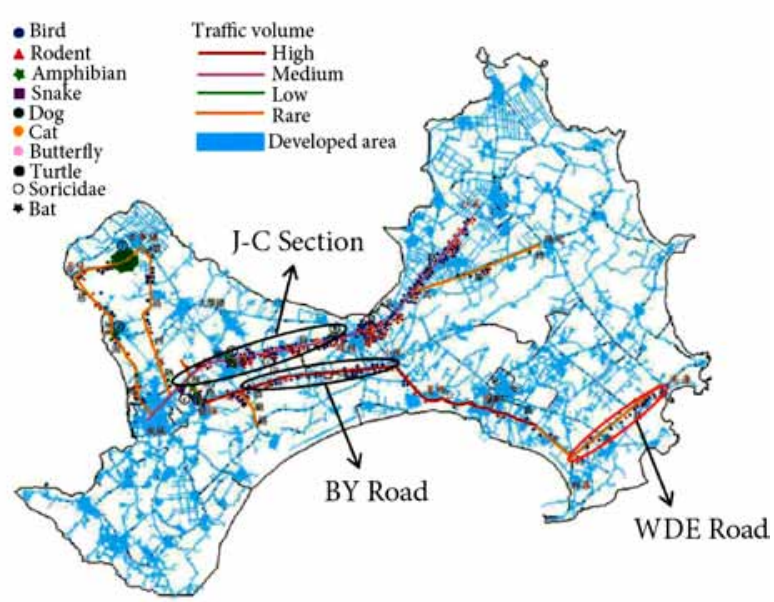

Fig. 1. The surveyed 8 roads in Kinmen and the locations of hot spots

Table 1. Summary of roadkills

\begin{tabular}{lccccccccccc}
\hline Species & Bird & Rodent & $\begin{array}{c}\text { Amphi- } \\
\text { bian }\end{array}$ & $\begin{array}{c}\text { Insec- } \\
\text { tivora }\end{array}$ & Snake & Cat & Turtle & Dog & Butterfly & Bat & Total \\
\hline Roadkills & 206 & 143 & 55 & 27 & 12 & 12 & 4 & 3 & 3 & 1 & 466 \\
\hline
\end{tabular}


Table 2. Rates of roadkill for each investigated road

\begin{tabular}{ccccc}
\hline Road & $\begin{array}{c}\text { Length } \\
(\mathrm{km})\end{array}$ & $\begin{array}{c}\text { Peak traffic } \\
\text { volume } \\
(\text { veh/hr) }\end{array}$ & $\begin{array}{c}\text { No. of } \\
\text { roadkills }\end{array}$ & $\begin{array}{c}\text { Average rate } \\
\text { of roadkills } \\
(\text { No./km/ } \\
\text { month) }\end{array}$ \\
\hline BL $^{*}$ & 0.74 & 283 & 18 & 324 \\
WDN & 12.45 & 151 & 250 & 1.67 \\
JR & 1.10 & 371 & 9 & $06 \$$ \\
WDW & 12.0 & 118 & 97 & 0.68 \\
UR & 0.50 & 42 & 3 & 0.50 \\
WDE & 3.25 & 80 & 18 & 0.46 \\
CR & 11.86 & 802 & 61 & 0.43 \\
GY & 4.10 & 216 & 7 & 0.14 \\
\hline
\end{tabular}

*The survey period of BL is only 7.5 months (1st, November, 2005 to 14 th, June, 2006). Widening BL started on 14th, June, 2006 and since then no roadkills have been spotted.

approaching. On the other hand, pollution, disturbance, road width, roadside trees, and animal populations are other important factors.

BL has the highest rate of roadkill even though its traffic flow and vehicle speeds are not high and its adjacent landscape is similar to that of other roads. BL road's slope is a special feature and an important ecological factor in increasing animal accidents. Two major wetlands, which are habitats of Kinmen amphibians, are located along a portion of WDW. Thus, during toad migration season, numerous Spectacled Toads (Bufo melanostictus) are run over by vehicles. It is evident that roadkills are related to habitat and season for most species. Tall and dense roadside trees along WDN and WDE roads attract wildlife to the roadside and, thereby, increase collision probability. The study of roadkill hot spot locations can help identify the dominant factors which affect animal accidents from a biological and, more importantly, an engineering point of view.

As researchers did not see animal accidents in person, the patterns of roadkill were unidentifiable. Since the patterns are significant in this study for modelling and analysis, we interviewed local taxi drivers and categorized four types of avian-vehicle collisions.

(I) Birds run over by vehicles as they stand or walk on the road.

(II) Birds hit by oncoming vehicles as they fly up from the road surface.

(III) Birds hit by vehicles as they fly across the road directly.

(IV) Birds hitting the side of vehicles as they fly into the road.

The interviews and observations did not find headon collisions between birds and vehicles. This suggests that birds can sense directly approaching objects but may only vaguely detect vehicles approaching at right angles.
Surveys found that categories (III) and (IV) account for $72 \%$ of bird accidents recorded. This suggests that birds have difficulty avoiding vehicles when flying across roads.

The four scenarios of avian-vehicle collision can also be applied to small mammals. Despite crossing at much lower speeds than birds, small mammals will not be able to survive if they collide with the side of a vehicle. Therefore, category (IV) still applies. With the knowledge of animal accident patterns, we can model roadkill probability.

\section{Modeling roadkill probability}

\subsection{Geometric model}

According to numerous researchers, traffic volume and vehicle speed are the major causes of roadkills (Forman et al. 2003; Reijnen et al. 1995). The higher the traffic volume or vehicle speed, the higher the roadkill probability. However, other factors, such as animal crossing speed and vehicle characteristics, are significant in assessing and predicting the probability. Based upon the investigation results and animal-vehicle collision patterns, two models are proposed in this study in order to predict the number of roadkills. First of all, we denote:

$-\lambda(\mathrm{no} . / \mathrm{sec}):$ Traffic volume in one direction.

$-V_{v}(\mathrm{~m} / \mathrm{sec})$ : Average speed of vehicles.

$-V_{a}(\mathrm{~m} / \mathrm{sec})$ : Animal crossing speed.

$-W_{v}(\mathrm{~m}):$ Average vehicle width.

$-L_{v}(\mathrm{~m})$ : Average vehicle length

The time, $t_{a}$ needed for an animal to cross a road is.

$$
t_{a}=\frac{W_{v}}{V_{a}} .
$$

As an animal enters into the "Impact Width" zone, $L_{i}$, defined as $L_{i}=L_{x}+L_{v}$ (Fig. 2), an accident will occur. $L_{x}$ is the distance ahead of vehicle that would cause category III accidents (hit by vehicle). $L_{v}$ is the range that causes category IV accidents (hit side of vehicle). $L_{x}$ can be obtained by the relationship

$$
L_{x}=V_{v} \cdot t_{a}=W_{v} \frac{V_{v}}{V_{a}} .
$$

Based on Eq. (2), the impact width is then

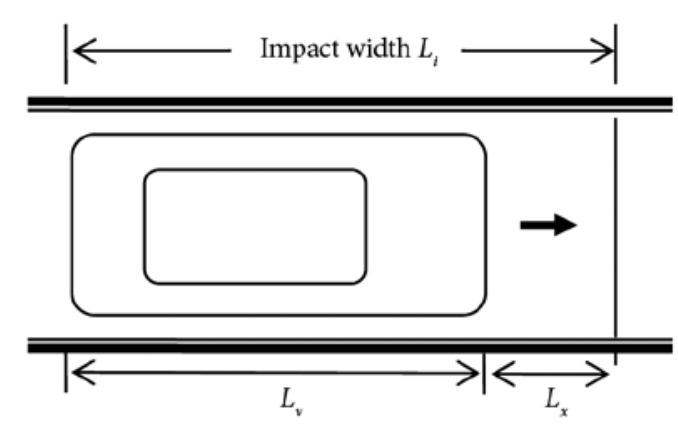

Fig. 2. The range of Impact Width consisting $L_{x}$ and $L_{v} L_{x}$ may cause roadkill scenario (III) and $L_{v}$ may cause roadkill scenario (IV) 


$$
L_{i}=L_{v}+L_{x}=L_{v}+W_{v} \frac{V_{v}}{V_{a}}
$$

The relationship between traffic volume $\lambda$ and average spacing of oncoming vehicles $\left(L_{\lambda}\right.$ in Fig. 3$)$ is

$$
\frac{L_{\lambda}}{V_{v}}=\frac{1}{\lambda} .
$$

Such that

$$
L_{\lambda}=\frac{V_{v}}{\lambda} .
$$

Figure 3 shows that the probability of animal accident is a geometric ratio of $L_{i} / L_{\lambda}$ that is defined as Geometric Model of roadkill probability $p$ as

$$
p=\frac{L_{i}}{L_{\lambda}}
$$

Substituting (3) and (5) into (6) yields

$$
p_{L}=\frac{L_{v}+W_{v} \frac{V_{v}}{V_{a}}}{\frac{V_{v}}{\lambda}}=\lambda\left(\frac{L_{v}}{V_{v}}+\frac{W_{v}}{V_{a}}\right) .
$$

Eq. (7) is a simple linear probability for animal accidents that may occur when crossing a single lane road. Here, we apply a geometric relationship to the distance between cars. The derivation is based on three assumptions:

(a) Road crossing behaviors of animals are stochastic and blind. Since it is not possible to include an animal's sense of danger or ability to avoid oncoming cars in a mathematic model, these factors were excluded from the derivative.

(b) For the same reason, the driver's reaction to crossing animals is also neglected.

(c) The case of extremely high traffic volume is excluded from the derivations since high traffic volume would make $L_{x}>L_{\lambda}$ (Overlap of impact width) and $p>1$ (Roadkill probability is greater than 1$)$.

\subsection{Traffic model}

Traffic Theory (Matson et al. 1971; May 1990) can also be used to predict the probability of accidents. Traffic Theory is used to derive the probability $\left(p_{x}\right)$ number of cars $(x)$ passing a certain checkpoint in time interval $t$ as a Poisson's distribution,

$$
p_{x}=\frac{e^{-\lambda t}(\lambda t)^{x}}{x !}
$$

Probability of an animal successfully crossing a single lane road $p_{o}$ (no car passes within time interval $t: x=0$ ) can be obtained based on Eq. (8) as,

$$
p_{0}=e^{-\lambda t}
$$

Van Langeveld and Jaarsma (2004) utilized this formula to discuss roadkill probability for mammals which

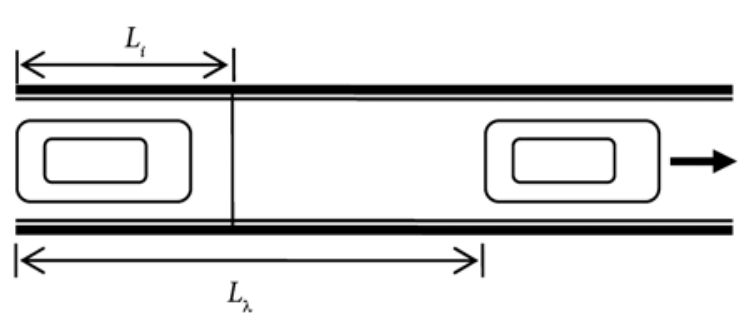

Fig. 3. Relationship of space between cars $\left(L_{\lambda}\right)$ and impact width $\left(L_{i}\right)$. The safety zone is $L_{\lambda}-L_{i}$ within which animals can cross the road safely

led to:

$$
p_{0}=e^{-\lambda\left(\frac{B+W_{r}}{V_{v}}\right)},
$$

where $B$ denotes body length of the animal and $W_{r}$ is road width. Since this study focuses on birds and small mammals, $B$ can be neglected and $W_{r}$ should be replaced by $W_{v}$. Because Eq. (10) considers $L_{x}$ as the entire impact range but does not include $L_{v}$ (Fig. 2). If the time of vehicle passing $L_{v}$ is taken into account, then the probability of a small animal successfully crossing a single lane road would be modified as

$$
p_{0}=e^{-\lambda\left(\frac{L_{v}}{V_{v}}+\frac{W_{v}}{V_{a}}\right)} .
$$

Hence, roadkill probability yields

$$
p_{T}=1-p_{0}=1-e^{-\lambda\left(\frac{L_{v}}{V_{v}}+\frac{W_{v}}{V_{a}}\right)} .
$$

Observing Eq. (12), we find that even though traffic volume $(\lambda)$ and vehicle speed $\left(V_{v}\right)$ are independent variables, there is an implicit correlation between them. In the case of constant traffic volume, the relationship can be clarified. In the case of high average vehicle speed: the ratio $L_{v} / V_{v}$ is small, the probability of an animal hitting the side of a vehicle is small. The second term of the exponent dominates the probability which implies that in this type of collision, the animal would be hit by the front of the vehicle. In the case of low average vehicle speed: the ratio $L_{v} / V_{v}$ becomes dominant which means that the space between vehicles is reduced and the probability of an animal hitting the side of the car increases. In this case, both vehicle length and speed are significant. When the average vehicle speed is extremely low, it resembles a traffic jam that leads to an accident probability approaching $100 \%$. To animals, this is like a wall on the road: each animal crossing will hit the side of a vehicle.

With low traffic volume, the difference between the Geometric Model and Traffic Model is insignificant, but traffic volume and vehicle speed are included in the models. While vehicle speed reflects the situation of side collisions, Eq. (10) (van Langevelde, Jaarsma 2004) does not consider it. Therefore, Eqs. (7) and (12) are more effective when considering small animal roadkill probability. 


\subsection{Modification of the models}

Still, the two equations cannot precisely predict roadkill probability since an animal's ability to dodge oncoming objects and the driver's reaction are neglected in the mathematical derivations. Pure mathematical models cannot predict or reflect complicated animal behaviors; therefore, more studies have to be conducted to understand animal conceptions of moving objects. However, our survey shows that adjacent landscape is also an important factor. If all the independent factors-landscape, driver's reaction, and animal behaviors-are included in the derivation, the final equations will be much more precise in predicting the probability of an accident. The three independent factors are denoted as:

(a) Landscape Factor $F_{L}$ (Including topography, road condition, adjacent vegetation and habitat).

(b) Driver's Factor $F_{D}$ (The reactions of a driver to the appearance of animals on the road).

(c) Animal Factor $F_{A}$ (The animal's ability to dodge oncoming vehicles).

The numerical value of each factor is between 0 and 1 but needs to be determined by experiment or survey. Including the three factors in the derivation, Eqs. (7) and (12) are modified and yield

$$
\bar{p}_{L}=p_{L} \cdot F_{L} \cdot F_{D} \cdot F_{A}=\lambda\left(\frac{L_{v}}{V_{v}}+\frac{W_{v}}{V_{a}}\right) \cdot F_{L} \cdot F_{D} \cdot F_{A}
$$

(Geometric Model);

$$
\bar{p}_{T}=p_{T} \cdot F_{L} \cdot F_{D} \cdot F_{A}=\left[1-e^{-\lambda\left(\frac{L_{v}}{V_{v}}+\frac{W_{v}}{V_{a}}\right)}\right] \cdot F_{L} \cdot F_{D} \cdot F_{A}
$$

(Traffic Flow Model).

These equations provide more representative models and can be used as tools in planning or designing roads.

\section{Testing roadkill models}

To test the models, two roads with similar surrounding landscapes are selected to compute the roadkill probabilities. The WDN road J-C section and WDE road have a total length of $5.44 \mathrm{~km}$ and $3.25 \mathrm{~km}$ respectively (landscapes shown in Figs 4 and 5). J-C section of WDN Road is with dense roadside trees of beef wood (Casuarina equisetifolia) and its both sides of the road are mostly sorghum farmlands and are birds' favorite foraging places. Landscape of WDE Road has dense roadside trees. Both sides of the road are mostly natural areas and habitats of various kinds of wildlife. The models are also applied to examine the ecological characteristics of BY Road (part of CR Road with a total length of $5.85 \mathrm{~km}$ and landscape shown in Fig. 6). BY Road is the widest road in Kinmen with the highest traffic volume. The original roadside trees (beef wood) were replaced by camphor trees (Cinnamomum camphora) after a typhoon hit Kinmen in 2000. It can be seen that the landscape of BY Road is quite distinct from WDN and WDE Roads and this may imply some different ecological features of the roads. The traffic data of the three roads are summarized in Table 3.

Table 3. Traffic information for J-C section, WDE and BY

\begin{tabular}{|c|c|c|c|c|c|}
\hline Road & $\begin{array}{c}\text { Length } \\
(\mathrm{km})\end{array}$ & $\begin{array}{l}\text { Average } \\
\text { vehicle } \\
\text { speed } \\
(\mathrm{km} / \mathrm{hr})\end{array}$ & $\begin{array}{c}\text { Penk traffic } \\
\text { volume } \\
(\text { No./hr })\end{array}$ & $\begin{array}{l}\text { Roadkills } \\
\text { (bird } \\
\text { rodent) }\end{array}$ & $\begin{array}{c}\text { Total } \\
\text { roadkills }\end{array}$ \\
\hline \multirow{2}{*}{$\begin{array}{l}\mathrm{J}-\mathrm{C} \text { of } \\
\mathrm{WDN}\end{array}$} & \multirow{2}{*}{5.44} & \multirow{2}{*}{60} & $\begin{array}{c}221 \text { (East } \\
\text { bound) }\end{array}$ & \multirow{2}{*}{$50 / 63$} & \multirow{2}{*}{113} \\
\hline & & & $\begin{array}{c}150 \text { (West } \\
\text { bound) }\end{array}$ & & \\
\hline \multirow{2}{*}{ WDE } & \multirow{2}{*}{3.25} & \multirow{2}{*}{60} & $\begin{array}{c}45 \text { (North } \\
\text { bound) }\end{array}$ & \multirow{2}{*}{$10 / 5$} & \multirow{2}{*}{15} \\
\hline & & & $\begin{array}{l}35 \text { (South } \\
\text { bound) }\end{array}$ & & \\
\hline \multirow{2}{*}{ BY } & \multirow{2}{*}{5.85} & \multirow{2}{*}{70} & $\begin{array}{c}369 \text { (East } \\
\text { bound) }\end{array}$ & \multirow{2}{*}{$36 / 4$} & \multirow{2}{*}{40} \\
\hline & & & $\begin{array}{l}433 \text { (West } \\
\text { bound) }\end{array}$ & & \\
\hline
\end{tabular}
Roads

Since the roadside trees and adjacent landscapes of the two roads are similar, we assume that the $F_{L}, F_{D}$, and $F_{A}$ of J-C are equal to those of WDE. Bird flight speeds vary greatly depending on the species. Bramblings fly $24 \sim 88 \mathrm{~km} / \mathrm{hr}$, Crows $80 \sim 90 \mathrm{~km} / \mathrm{hr}$, Heron $29 \sim 46 \mathrm{~km} / \mathrm{hr}$, and Osprey $66 \mathrm{~km} / \mathrm{hr}$ (Tyne, Berger 1959). Furthermore, speeds during road-crossing or take off tend to be significantly lower than normal flight. It is, therefore, very difficult to ascertain the flight speed. However, flight speed $V_{a}$ does not significantly affect the results

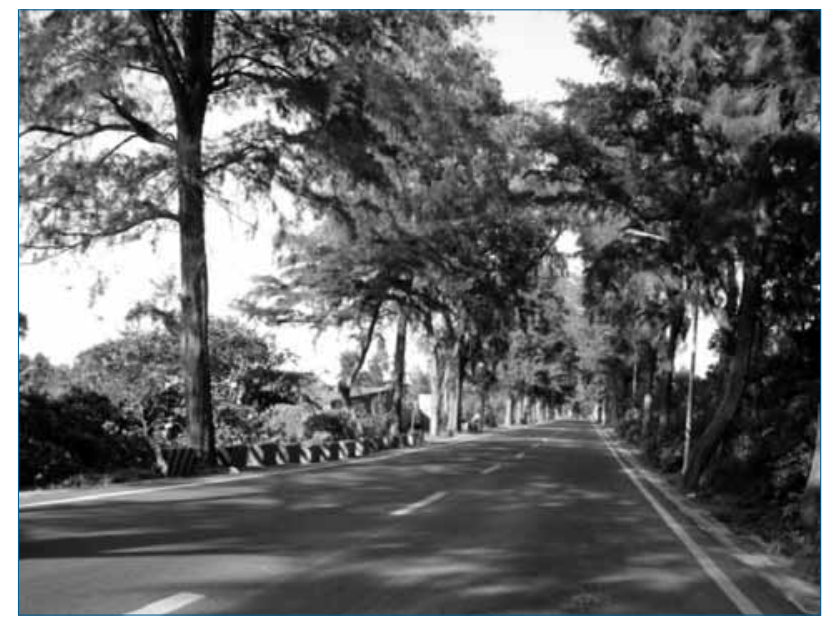

Fig. 4. Landscape of J-C section of WDN Road 


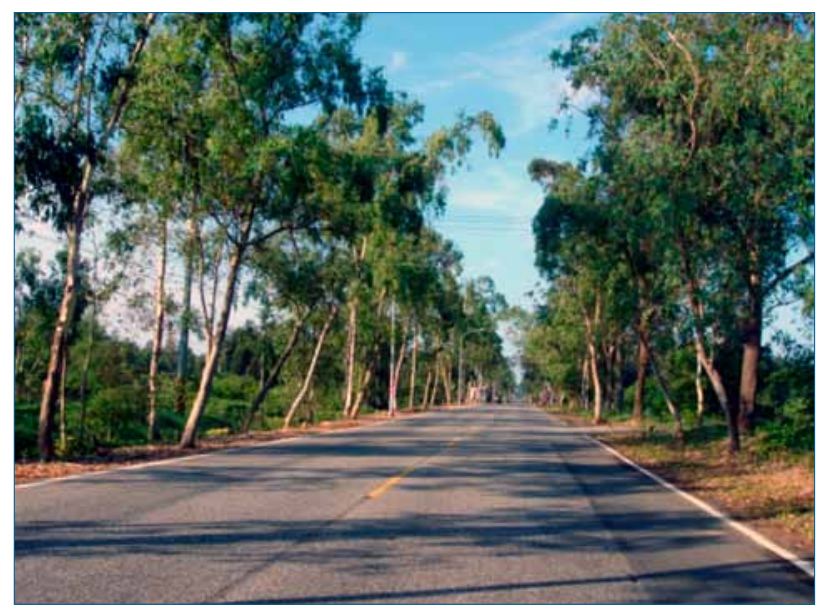

Fig. 5. Landscape of WDE Road

in the models; therefore, the average speed is assumed to be $V_{a}=40 \mathrm{~km} / \mathrm{hr}$. In addition, the crossing speed of small mammals (mostly rodents) is assumed to be $V_{a}$ $=10 \mathrm{~km} / \mathrm{hr}$. The average crossing speed for animals is then $V_{a}=25 \mathrm{~km} / \mathrm{hr}$. To test the models and carry out the computation, some assumptions are made as follows: the average vehicle length is $L_{v}=5 \mathrm{~m}$, vehicle width is $W_{v}$ $=2.5 \mathrm{~m}$, then taking double lanes into consideration. Animal roadkill probability $p_{L}$, by Geometric Model, gives us:

$$
p_{L}=1-\left[1-\lambda_{1}\left(\frac{L_{v}}{V_{v}}+\frac{W_{v}}{V_{a}}\right)\right]\left[1-\lambda_{2}\left(\frac{L_{v}}{V_{v}}+\frac{W_{v}}{V_{a}}\right)\right] .
$$

Then, the modified Geometric Model probability is:

$$
\begin{aligned}
& \bar{p}_{L}=p_{L} \cdot F_{L} \cdot F_{D} \cdot F_{A}=\left\{1-\left[1-\lambda_{1}\left(\frac{L_{v}}{V_{v}}+\frac{W_{v}}{V_{a}}\right)\right] .\right. \\
& \left.\left[1-\lambda_{2}\left(\frac{L_{v}}{V_{v}}+\frac{W_{v}}{V_{a}}\right)\right]\right\} \cdot F_{L} \cdot F_{D} \cdot F_{A} .
\end{aligned}
$$

While the Traffic Model, $p_{T}$, yields:

$$
p_{T}=1-\left[e^{-\lambda_{1}\left(\frac{L_{v}}{V_{v}}+\frac{W_{v}}{V_{a}}\right)}\right]\left[e^{-\lambda_{2}\left(\frac{L_{v}}{V_{v}}+\frac{W_{v}}{V_{a}}\right)}\right] .
$$

The modified Traffic Flow Model probability is then:

$$
\begin{aligned}
& \bar{p}_{T}=p_{T} \cdot F_{L} \cdot F_{D} \cdot F_{A}= \\
& \left\{1-\left[e^{-\lambda_{1}\left(\frac{L_{v}}{V_{v}}+\frac{W_{v}}{V_{a}}\right)}\right]\left[e^{-\lambda_{2}\left(\frac{L_{v}}{V_{v}}+\frac{W_{v}}{V_{a}}\right)}\right]\right\} \cdot F_{L} \cdot F_{D} \cdot F_{A} .
\end{aligned}
$$

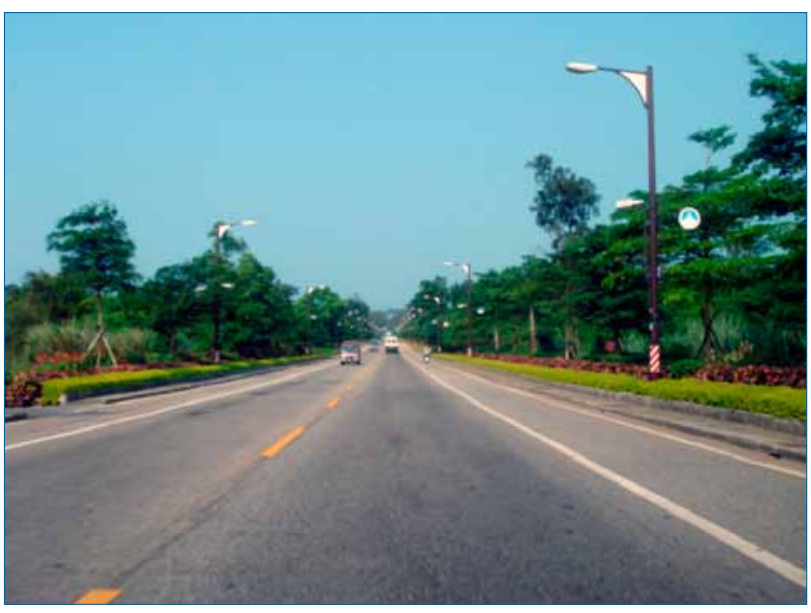

Fig. 6. Landscape of BY Road

\subsection{Comparing roadkill probability for the J-C section and WDE road}

Substituting the data into Eqs (16) and (18), the ratio of roadkill probability $r_{(\mathrm{J}-\mathrm{C} / \mathrm{WDE})}$ can be obtained as

$$
\begin{aligned}
r_{L} & =4.52(\text { Geometric Model); } \\
r_{T} & =4.46 \text { (Traffic Flow Model). }
\end{aligned}
$$

The difference between the results of the two models is insignificant. To predict the number of roadkills $(X)$ along WDE we utilize the number of roadkills from the $\mathrm{J}-\mathrm{C}$ section, and establish the relationship:

$$
\frac{X}{3.25} \cdot r_{L}=\frac{113}{5.44} \text {. }
$$

Then, we have

$X=14.9$ (Geometric Model), and $X=15.1$ (Traffic Model),

which is surprisingly consistent with our observations (15 roadkills on WDE). The result confirms the previous assumption that $F_{L}, F_{D}$, and $F_{A}$ are identical for J-C and WDE roads. Since unknown factors are eliminated, the roadkill numbers for WDE can be predicted. If we take $V_{a}=40 \mathrm{~km} / \mathrm{hr}$ and $V_{a}=10 \mathrm{~km} / \mathrm{hr}$ and apply Traffic Flow Model, $X=15.0$ and $X=15.4$ are obtained. This implies that the animal crossing speeds are insignificant in this case. As adjacent landscapes are similar, the models can be applied to predict the number of roadkills.

\subsection{Probability ratio comparison between $\mathrm{J}-\mathrm{C}$ section and $\mathrm{BY}$ roads}

With regards to landscape, $\mathrm{J}-\mathrm{C}$ section has high and dense beef woods while BY Road has low and dispersed camphor trees. Also, BY Road, the major commuting conduit in Kinmen, is wide and experiences high traffic volume. The distinct difference between these two roads should be 
a significant factor in the determination of roadkill probability. Substituting associated data into the models, $r_{(\mathrm{J}-\mathrm{C} /}$ ВY) is computed as:

$$
\begin{aligned}
& \text { (23) } r_{L}=0.504 \frac{\left(F_{L}\right)_{J-C}}{\left(F_{L}\right)_{B Y}} \text { (Geometric Model); } \\
& \text { (24) } r_{T}=0.512 \frac{\left(F_{L}\right)_{J-C}}{\left(F_{L}\right)_{B Y}} \text { (Traffic Flow Model). }
\end{aligned}
$$

Knowing the number of the roadkills on J-C section, the number of animal casualties of BY $(X)$ is calculated with the relationship:

$$
\frac{X}{5.85} \cdot r=\frac{113}{5.44} .
$$

Assuming that the landscape factors of the two roads are equal, $\left(F_{L}\right)_{\mathrm{J}-\mathrm{C}}=\left(F_{L}\right)_{\mathrm{BY}}$, the roadkills of BY road are:

$$
\begin{gathered}
X=241 \text { (Geometric Model) and } \\
X=237 \text { (Traffic Flow Model), }
\end{gathered}
$$

respectively. The results differ greatly from our observations (40 roadkills on BY) and the assumptions about landscape factors are not confirmed. Instead of equal landscape factors $\left(F_{L}\right)_{\mathrm{J}-\mathrm{C}}=\left(F_{L}\right)_{\mathrm{BY}}$ for the two roads, $\left(F_{L}\right)_{\mathrm{J}-\mathrm{C}}=$ $6 \times\left(F_{L}\right)_{\mathrm{BY}}$ would produce $X \cong 40$ which means that the landscapes of the two roads are significantly distinct and are reflected in the calculation. Since J-C section and BY road are parallel and only about $1 \mathrm{~km}$ apart, we can assume that the adjacent ecosystems, and animal population and composition are similar for the two roads. Expressions of (26) reveal that the probability of roadkill occurring on $\mathrm{J}$-C section is 6 times higher than on BY road and implies that the landscape of J-C section is prone to causing more animal accidents. We can then conclude that higher traffic volume increases roadkill probability; but, the traffic may also become a barrier blocking animal crossing. Noise, pollution, and disturbance may cause birds to fly across roads at higher altitudes or avoid mammals approaching the roads. Thus, fewer bird collisions take place along BY road. In addition, increased road width and traffic prevent birds from foraging on the road; therefore, reducing avian roadkill probability. This assessment may be an important tool in planning, designing and constructing an ecologically friendly road.

\subsection{Inclined roads (BL road)}

Among the surveyed roads, BL is the most intriguing because it has the highest roadkill probability among the roads surveyed. Fifteen roadkills ( 9 birds, 2 rodents, 1 frog, 1 snake, 1 unidentified) occurred along BL road as vehicles descended the slope but only four (2 birds, 1 rodent, 1 cat) as they ascended. The ratio of bird roadkills is, therefore, $9 / 2=4.5$ (down/up slope). Since traffic volume is low, Eqs (13) and (14) can be utilized. The average vehicle speed on decline and incline are measured as $55.7 \mathrm{~km} / \mathrm{hr}$ and $49.8 \mathrm{~km} / \mathrm{hr}$ respectively. The road width is $6 \mathrm{~m}$, and its peak traffic volume is 140 vehicles per hour while off peak is 75 vehicles per hour. By applying the models to avian roadkill to find roadkill ratio $r$ (down/ up), with the assumption that $L_{v}=5 \mathrm{~m}, W_{v}=2.5 \mathrm{~m}$, and $V_{a}=40 \mathrm{~km} / \mathrm{hr}$, we find that $r=1.045$ for the Geometric Model and $r=1.045$ for the Traffic Flow Model. This means that the number of roadkills that occur over the course of the downward gradient is only 1.045 times that of the upward. The minor difference between the values suggests that vehicle speed is not the major cause of bird roadkill on BL road.

The difference in values indicates that slope may be a factor. As a vehicle travels up the gradient, it is more visible to birds crossing the road. When it travels down, the vehicle visually blends into the road surface. Many varieties of birds view objects using rapid spiral scan (saccades) with a magnitude of $10^{\circ} \sim 12^{\circ}$ (Wallman, Letelier 1993). With BL road slope of $2.04^{\circ}$ (or $4.2 \%$ ), the bird's visual range up the gradient is only (assuming a scan magnitude $\left.11^{\circ}\right) 11^{\circ} / 2-2.04^{\circ}=2.96^{\circ}$, while down the slope it is $11^{\circ} / 2+2.04^{\circ}=7.54^{\circ}$. This difference contributes to the varying results of opposing gradients. Also, the accidents that took place on this road were most likely birds run over by vehicles as they were walking or foraging on the road. Only birds walking or standing on the road have an obstructed view, hence flying over can be excluded as factor in the accidents.

We can confirm that the slope of the road is the major factor of roadkills on BL road by observing the changes of road conditions. Since 1.5 months after survey commenced, BL road has been in the process of being widened. In the first 3 months of construction, only roadside grading was undertaken and traffic remained normal. More importantly, birds could fly over the road during this period of time; however, no bird casualties were discovered after the commencement of construction. If the avian casualties found before the start of construction were the result of normal avianvehicle collisions, further fatalities should have been recorded during construction as well. This may confirm the speculation that most of the avian deaths occurred as the birds walked or foraged on the road and, due to road gradient, had an obstructed view of oncoming traffic. Therefore, this unusual roadkill phenomena can be studied by applying our models.

\subsection{The effects of roadside trees on roadkill}

Roadside trees influence the occurrence of avian-vehicle collisions. Attributes such as density, height, leaves and branches are all factors. Dense leaves and branches can 


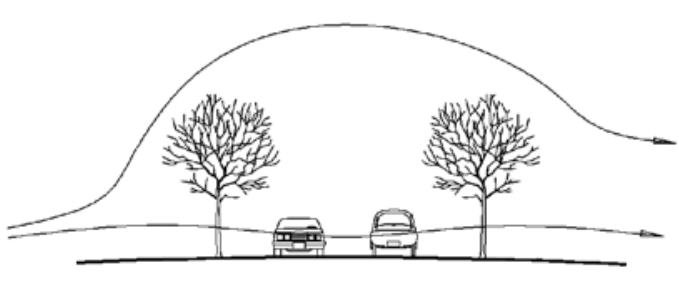

Fig. 7. Leaves and branches of roadside trees block part of flying route of birds.

block part of flying route of birds. Most birds, especially understory species, would fly crossing the road between trunks of trees whose height is almost coincident with vehicles'. Therefore this type of roadside tree arrangement would increase avian roadkill probability (Fig. 7). Observations along WDN Road confirm this scenario.

To estimate the impact roadside trees have on the occurrence of avian roadkill, four roads in Kinmen were selected to observe, record, and assess:

(a) WDN Road near Shiao-Jin Road: The south side of the road is mainly farmland and the north side is about 1 hectare of woodland bird habitat.

(b) CR Road (between Cheng-Kong and Shia-Shin): This part of CR runs east-west. There is a small forest on the north side of the road and another forest at a lower altitude on the south side.

(c) WDN Road (between Chiong-Lin and Ho-Pan): Both sides of the road are farmland. The roadside trees are high and dense beef woods.

(d) WDW Road: The adjacent landscapes of both side of the road are farmland. Similar to WDN Road, the roadside trees are mainly beef woods.

The observations of the four roads are shown in Table 4 .
It is obvious that the probability of birds flying into the "Impact Zone" will be much higher for (c) and (d) (high and dense beef woods) than the other two roads. We can conclude that dense roadside trees cause birds to cross the road at a lower altitude which leads to more avian casualties and a greater landscape factor $\left(F_{L}\right)$. In fact, the observation of avian roadkills along all eight roads also confirms this phenomenon.

\section{Suggestions}

\subsection{Mitigation measures for avian roadkills}

\subsubsection{Topography}

Flying birds' migration patterns generally follow certain terrain and vegetation criteria (Bevanger, Brøseth 2004). The height of flight is also dependent upon the height of vegetation (Ramp et al. 2006). Consequently, fewer birds are killed on raised roads as opposed to roads on flat terrain (Clevenger et al. 2003) because the topography forces birds to fly high over the roads and prevents collisions with oncoming cars. Therefore, a raised road bed or altered surrounding vegetation will reduce avian-vehicle collisions.

\subsubsection{Vegetation}

High and dense roadside trees increase the probability of accidents involving avian species. In order to decrease this probability, vegetation can be designed to influence bird flight patterns and direct them over the road safely as shown in Figure 8. Certain aspects (such as trash, temperature, and water) may attract birds to forage on the road surface; however, with this type of vegetation, the chance of birds foraging on the road is lower, thus, reducing collision probability.

Table 4. Flight patterns over roads with various forms of roadside trees

\begin{tabular}{|c|c|c|c|c|c|c|}
\hline Road & $\begin{array}{l}\text { Attributes of } \\
\text { roadside trees }\end{array}$ & Observation time & $\begin{array}{c}\text { Effective } \\
\text { observation range }\end{array}$ & $\begin{array}{c}\text { Number of birds } \\
\text { flying into Impact } \\
\text { Zone }^{*}\end{array}$ & $\begin{array}{l}\text { Number of birds } \\
\text { flying away from } \\
\text { Impact Zones }\end{array}$ & $\begin{array}{l}\text { Total number of } \\
\text { birds observed }\end{array}$ \\
\hline (a) & Low and dispersed & $17: 15 \sim 18: 15$ & $100 \mathrm{~m}$ & 5 & 71 & 76 \\
\hline (b) & Low and dispersed & $17: 05 \sim 18: 35$ & $200 \mathrm{~m}$ & 10 & 75 & 15 \\
\hline$(c)^{* *}$ & High and dense & $17: 05 \sim 18: 40$ & $300 \mathrm{~m}$ & $\begin{array}{c}95 \\
\text { (15 birds walking } \\
\text { on the road) }\end{array}$ & 41 & 135 \\
\hline$(c)^{* * *}$ & High and dense & $16: 55 \sim 18: 15$ & $900 \mathrm{~m}$ & $\begin{array}{c}155 \\
\text { (24 birds walking } \\
\text { on the road) }\end{array}$ & 125 & 210 \\
\hline (d) & High and dense & $16: 00 \sim 18: 00$ & $100 \mathrm{~m}$ & $\begin{array}{c}49 \\
\text { (1 bird walking on } \\
\text { the road) }\end{array}$ & 37 & 16 \\
\hline
\end{tabular}

Note: ${ }^{\star}$ The Impact Zone is defined as the range between road surface and $2 \mathrm{~m}$ below; ${ }^{\star \star}$ Observed by bare eyes; ${ }^{\star * \star}$ Observed by telescope. 


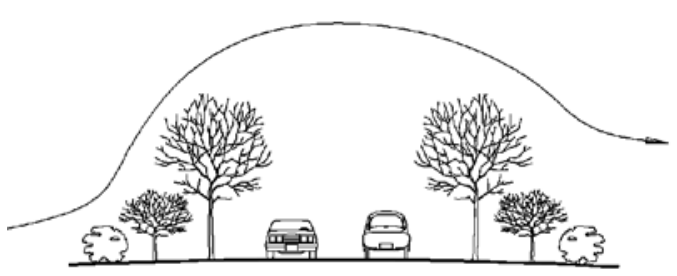

Fig. 8. Reducing avian roadkills by vegetation arrangement which is to plant trees and shrubs in upward trend to guide birds fly higher over a road

\subsubsection{Spacing of vegetation}

Gaps in linear vegetation (such as roadside trees) become avian migration conduits and, in turn, roadkill hot spots. Therefore, vegetation should not have gaps in the vicinity of high traffic volume sections of a road.

\subsubsection{Road attributes}

\subsubsection{Sloping road hot spots}

As observed on BL road, the probability of avian roadkill is greater on negatively sloping sections then positive due to higher vehicle speeds and lower visibility for birds at risk. At high speeds, drivers have a limited time to respond to emerging birds. The same is true for birds attempting to avoid oncoming vehicles. Lowering vehicle speeds can reduce collisions. Flattening slopes and installing warning signs and speed bumps will reduce vehicle speeds and, in turn, give drivers and animals more time to respond.

\subsubsection{Curving section hot spots}

Limited vision at sharp corners causes insufficient response time for both drivers and animals and increases the chance of collision. Straightening abrupt turns or clearing nearby obstacles can improve the visibility and lower roadkill probability. Where these two methods can not be implemented, installing warning signs and lowering the speed limit are also effective measures.

\subsubsection{Flat or depressed surface hot spots}

Birds tend to follow the terrain and fly into flat or depressed road surfaces and, therefore, cause accidents. Raising the road bed to guide birds over the road is another way to reduce avian roadkill. However, the barrier effect of this engineering method has to be considered before designing the road.

\subsubsection{Traffic volume and speeds}

\subsubsection{Traffic volume}

According to our models, traffic volume is obviously the most influential factor in determining the probability of roadkill. Lower speed limits and reduced traffic volume are the most effective measures to implement. If hot spots are located in high traffic areas, diverting traffic to alternative routes is an option. Other measures to lower traffic volume can be considered: building underpasses or overpasses at hot spots, temporarily closing roads in high casualty seasons, encouraging public transportation, and subsidizing car pooling.

\subsubsection{Vehicle speed}

For drivers, speed reduces the visual field, restricts peripheral vision and limits the time available to receive and process information (AASHT 2001). Low vehicle speed can not only reduce roadkills but also lower noise intensity and prevent barrier effects. Reducing speed limits, installing speed bumps and radar, putting up traffic signals, and establishing warning signs in routes are methods that can be implemented to lower vehicle speeds.

\subsection{Mitigation measures for terrestrial animals}

On Kinmen, small mammals, amphibians and reptiles are the most common terrestrial animals; among them, rodents and frogs are the most common victims of roadkill. On April (157 days after survey commenced), on WDW road, 29 Spectacled toads were killed by vehicles on roads adjacent to Suan-Li wetland. This suggests that some amphibians migrate at certain times during mating season. For this specific species, roadkill may be mitigated by temporarily closing the road or installing temporary underpasses (or overpasses) at the hot spots.

Mitigation measures for terrestrial animals are dependent upon species. To prevent terrestrial animal roadkill, passages are the most common. However, vegetation and fences have to be considered as well in order to achieve best results. Guidelines for installing passages are: (a) close to animal habitat, (b) close to animal migration routes, (c) close to hot spots or locations where animals frequently appear, and (d) connect animal habitats. The location and adjacent landscape are also important factors for the success of the passages. Therefore, the surroundings of the passages should adhere to the following: (a) a small wetland near passage to attract animals, (b) regular checks to ensure a clear entrance to the passage, (c) fences to lead animals to the entrance while maintaining metapopulation dynamics, (d) guiding facilities such as slopes, curves, ditches, etc. that allow animals to access the passage, and (e) reduced human access or disturbances (Lin 2006).

\section{Conclusions}

Based on our research, three aspects influence the probability of roadkill. Firstly, the comparison of J-C section and WDE road proves that if surrounding landscapes 
are similar there is a positive correlation between traffic volume and roadkill probability thus giving us the 'RoadTraffic aspect'. In this case, traffic volume is the most significant factor affecting the probability. In addition, vehicle speed, car length, and animal crossing speed can also determine the frequency of animal accidents. If the traffic volume is high but vehicle speed low, the traffic will be congested and most accidents will consist of an animal hitting the side of a vehicle. Thus, roadkill probability increases. On the other hand, with a constant traffic volume but high vehicle speed, the length of vehicle becomes unimportant and most accidents will be head-on collisions.

Secondly, roadkill probably is high when roads pass through natural habitats or bisect animal migration routes. This situation is referred to as, the 'Landscape aspect'. It involves the direct engagement of humans and animals. Tall and dense roadside trees cause higher animal casualties, especially among understory avian species, by attracting animals and changing the flight patterns of avian species. While, low roadside trees, wide road surfaces, or high traffic flow (see BY road) form an ecological barrier, restrict the movement of some species, and, therefore, reduce gene exchange.

Finally, the 'Biological aspect' refers to the fact that, in general, most drivers will slow down to avoid hitting animals and, therefore, lower the accident rate. Many animals also possess the ability to avoid collisions. For species that are accomplished fliers (such as the Barn Swallow and Chestnut bat), their agility greatly reduces the risk of accident even when they congregate in great numbers at the roadside. In contrast, slow moving animals such as reptiles and amphibians cross the road with great risk. These biological factors cannot be precisely determined and more research on these subjects needs to be undertaken. Nevertheless, applying models that incorporate similar landscapes around different roads, accident probabilities may be effectively obtained without knowing the influence of biological factors.

\section{Acknowledgements}

This work was supported by National Science Council of ROC in Taiwan grant no. NSC 103-2621-M-507-002.

\section{References}

Adams, L. W.; Geis, A. D. 1983. Effects of roads on small mammals, Journal of Applied Ecology 20: 403-415. http://dx.doi.org/10.2307/2403516

Bennett, A. F. 1992. Roads, roadsides, and wildlife conservation: a review, in D. A. Saunders, R. J. Hobbs (Eds.). Nature conservation 2: the role of corridors. Surrey Beatty and Sons, 99-118.

Bevanger, K.; Brøseth, H. 2004. Impact of power lines on bird mortality in a subalpine area, Animal Biodiversity and Conservation 27(2): 67-77.
Clevenger, A. P.; Chruszcz, R.; Gunson, K. E. 2003. Spatial patterns and factors influencing small vertebrate fauna road-kill aggregations, Biological Conservation 109: 15-26. http://dx.doi.org/10.1016/S0006-3207(02)00127-1

Dhindsa, M. S.; Sandhu, J. S.; Sandhu, P. S.; Toor, H. S. 1988. Roadside birds in Punjah (India): Relation to mortality from vehicles, Environmental Conservation 15(4): 303-310. http://dx.doi.org/10.1017/S0376892900029799

Forman, R. T. T. 1995. Land mosaics: the ecology of landscapes and regions. Cambridge University Press.

Forman, R. T. T.; Sperling, D.; Bissonette, J. A.; Clevenger, A. P.; Cutshall, C. D.; Dale, V. H.; Fahrig, L.; France, R.; Goldman, C. R.; Heanue, K.; Jones, J. A.; Swanson, F. J.; Turrentine, T.; Winter, T. C. 2003. Road ecology, science and solutions. Washington: Island Press.

Gunther, K. A.; Biel, M. J.; Robison, H. L. 1998. Factors influencing the frequency of road-killed wildlife in Yellowstone National Park, in Proceedings of the International Conference on Wildife Ecology and Transportation, 10-12 February 1998, Fort Myer, Florida, 32-36.

Jaarsuma, C. F.; Willems, G. P. A. 2002. Reducing habitat fragmentation by minor rural roads through traffic calming, Landscape and Urban Planning 58: 125-135. http://dx.doi.org/10.1016/S0169-2046(01)00215-8

Lin, S. C. 2006. A review for the types of wildlife passages, Journal of National Park 16(1): 83-98 (in Chinese).

Matson, T. M.; Smith, W. S.; Hurd, F. W. 1971. Traffic engineering. New York: McGraw-Hill.

May, A. D. 1990. Traffic flow fundamentals. Englewood Cliffs: Prentice-Hall, Inc.

McDonald, W. R.; St. Clair, C. C. 2004. The effects of artificial and natural barriers on the movement of small mammals in Banff National Park, Canada, Oikos 105: 39-407.

Nankinov, D. N.; Todorov, N. M. 1983. Bird casualties on highway, Soviet Journal of Ecology 42: 594-596.

Ramp, D.; Wilson, V. K.; Crof, D. B. 2006. Assessing the impacts of roads in peri-urban reserves: Road-based fatalities and road usage by wildlife in the Royal National Park, New South Wales, Australia, Biological Conservation 129: 348-359. http://dx.doi.org/10.1016/j.biocon.2005.11.002

Reijnen, R.; Foppen, R.; ter Braak, C.; Thissen, J. 1995. The effects of car traffic on breeding bird populations in woodland III, Reduction of density in relation to the proximity of main roads, Journal of Applied Ecology 32: 187-202. http://dx.doi.org/10.2307/2404428

Seiler, A. 2001. Ecological effects of roads, a review. Riddarhytan: University of Agriculture Sciences.

Slater, P. 1994. Wildlife road casualties, British Wildlife 5: 214-221.

Tyne, J. V.; Berger, A. J. 1959. Fundamentals of ornithology. New York: John Wiley and Sons, Inc.

van Langevelde, F.; Jaarsma, C. F. 2004. Using traffic flow theory to model traffic mortality in mammals, Landscape Ecology 19: 895-907. http://dx.doi.org/10.1007/s10980-004-0464-z

Wallman, J.; Letelier, J-C. 1993. Eye movements, head movements, and gaze stability in bird, in H. P. Zeigler and H-J. Bischof (Eds.). Vision, brain and behaviour in birds. Cambridge: The MIT Press.

Wilson, E. O. 1989. Threats to biodiversity, Scientific American 261(3): 108-116.

http://dx.doi.org/10.1038/scientificamerican0989-108 
Shyh-Chyang LIN is an associate professor at the Department of Civil Engineering and Engineering Management at National Quemoy University in Taiwan. His research has been evolving from applied mechanics, engineering materials, to ecological engineering, island studies, and finally to social networking. The broad spectrum of his research interests allows him to explore deeper ecological, social, economical, and political issues. Currently, his research focuses on applications of social network technology, and scale issues of small islands. He was a recipient of Presidential Award for Environmental Conservation in 2005. 